\title{
Da abolição da escravatura às Ações Afirmativas: busca política por justiça e
}

\section{democracia}

\author{
From the abolition of slavery to Affirmative Action: political struggle for justice and democracy \\ De la abolición de la esclavitud a la Acción Afirmativa: lucha política por justicia y democracia
}

Recebido: 12/11/2021 | Revisado: 20/11/2021 | Aceito: 07/12/2021 | Publicado: 13/12/2021

Zilda Martins

ORCID: https://orcid.org/0000-0002-8772-0523

Universidade Federal do Rio de Janeiro, Brasil E-mail: zildamarti@yahoo.com.br

\begin{abstract}
Resumo
A reflexão proposta neste artigo incide sobre três eixos em torno da justiça e da democracia no Brasil ou sua incipiência. Ancora-se nas políticas públicas de Ações Afirmativas, a fim de pensar um novo socius. O primeiro eixo, injustiça como padrão, versará sobre a escravidão e a abolição. O segundo abordará as Ações afirmativas e a rejeição social das políticas públicas, sobretudo às cotas raciais, e o terceiro analisará o tema sociedade civil versus justiça e democracia. Questiona ambos os conceitos, assim como o racismo epistêmico e o eurocentrismo acadêmicos. Estarão as universidades apenas cumprimento a Lei das Cotas ou abertas a novos saberes? O objetivo do trabalho é refletir sobre a perspectiva de que o equilíbrio social, econômico, político e cultural depende do amplo engajamento da sociedade civil pelos direitos, reais e simbólicos, no combate ao racismo. Os resultados deste estudo indicam a manifestação de novos intelectuais negros na esfera publica, aparições de agendamento político e de novas epistemes. Metodologicamente, o estudo ampara-se no método sinóptico de Sodré (2014a), de caráter dialético-qualitativo e revisão bibliográfica, a partir de autores como Silvio Almeida (2019), Muniz Sodré (2014a, 2015), Françoise Vergès (2005), Michael Sandel (2012), Achille Mbembe (2018), Lélia Gonzalez (1982), Boaventura de Sousa Santos (2005), Gramsci (2007), Rancière (2018).
\end{abstract}

Palavras-chave: Ações afirmativas; Racismo e democracia; Justiça social.

\begin{abstract}
The reflection proposed in this article focuses on three axes around justice and democracy in Brazil or their incipience. It is anchored in the public policies of Affirmative Actions, in order to think of a new socius. The first axis, injustice as standard, will deal with slavery and its abolition. The second will address the Affirmative Actions and the social rejection of public policies, especially racial quotas, and the third will analyze the theme civil society versus justice and democracy. It questions both concepts, as well as the epistemic racism and academic eurocentrism. Are universities only complying with the Quota Law or open to new knowledge? The purpose of this work is to reflect on the perspective that the social, economic, political and cultural balance depends on the broad engagement of civil society for the rights, real and symbolic, in the fight against racism. The results of this study indicate the manifestation to the emergence of new black intellectuals in the public sphere, appearances of political agenda and new epistemes. Methodologically, this study is supported by Sodré's (2014a) synoptic method, of dialecticalqualitative character and bibliographical review, from authors such as Silvio Almeida (2019), Muniz Sodré (2014a, 2015), Françoise Vergès (2005), Michael Sandel (2012), Achille Mbembe (2018), Lélia Gonzalez (1982), Boaventura de Sousa Santos (2005), Gramsci (2007), Rancière (2018).
\end{abstract}

Keywords: Affirmative Actions; Racism and democracy; Social justice.

\section{Resumen}

La reflexión propuesta en este artículo se centra en tres ejes en torno a la justicia y la democracia en Brasil o su incipiencia. Está anclado en las políticas públicas de Acciones Afirmativas, para pensar en un nuevo sujeto social. El primer eje, la injusticia como norma, se ocupará de la esclavitud y la abolición. El segundo abordará las Acciones Afirmativas y el rechazo social a las políticas públicas, especialmente las cuotas raciales, y el tercero analizará el tema sociedad civil versus la justicia y la democracia. Cuestiona ambos conceptos, así como el racismo epistémico académico y el eurocentrismo. ¿Están las universidades simplemente cumpliendo con la Ley de Cuotas o abiertas a nuevos conocimientos? El objetivo del trabajo es reflexionar sobre la perspectiva de que el equilibrio social, económico, político y cultural depende del amplio compromiso de la sociedad civil por los derechos, reales y simbólicos, en la lucha contra el racismo. Los resultados de este estudio indican la manifestación de nuevos intelectuales negros en la esfera pública, apariciones de agenda política y nuevas epistemes. Metodológicamente, el estudio se sustenta en el método sinóptico de Sodré (2014a), de carácter dialético-cualitativo y revisión bibliográfica 
de autores como Silvio Almeida (2019), Muniz Sodré (2014a, 2015), Françoise Vergès (2005), Michael Sandel (2012), Achille Mbembe (2018), Lélia González (1982), Boaventura de Sousa Santos (2005), Gramsci (2007), Rancière (2018).

Palabras clave: Acciones afirmativas; Racismo y democracia; Justicia social.

\section{Introdução}

A reflexão proposta neste trabalho incide sobre três eixos em torno da justiça e democracia no Brasil ou sua incipiência, diante de uma sociedade que clama por direitos e diversidade. Ancora-se nas políticas públicas de Ações Afirmativas e cotas raciais, resultado de reivindicações antigas dos movimentos negros por combate ao racismo, direito à educação e reconhecimento. Parte das análises serão extraídas da tese de doutorado da autora. O primeiro eixo, injustiça como padrão, versará sobre a escravidão, instituída e naturalizada na prática cotidiana por mais de três séculos; e sobre a abolição, cuja Lei Áurea de apenas dois artigos, portava em si mesma o esquecimento da população negra. Questiona a justiça da Monarquia, mantenedora do sistema escravocrata, baseado na economia sob a manutenção de seres humanos como coisas, moeda de troca, logo destituídos de ontologia. Lembra a Constituição Imperial de 1924, que tinha caráter liberal, portanto, incoerente com a escravidão, mas indiretamente fazia referência a esse sistema. À época, a justiça considerava os fundamentos da economia justificáveis à existência da escravidão. E, na contemporaneidade, o que justifica a desigualdade?

O segundo eixo a ser analisado são as Ações Afirmativas e a rejeição às políticas públicas, em pauta no início deste século, no Brasil, mobilizando, de um lado, os movimentos negros e suas reivindicações e, de outro, a mídia tradicional e o discurso contra as cotas raciais, uma das modalidades das ações afirmativas. A análise versará sobre a emergência de um discurso midiático reatualizado do século XIX; forte oposição às cotas raciais e defesa das cotas sociais, que sequer tinham entrado no bojo das lutas iniciais. Aponta como consequência dos discursos a formação da opinião pública de caráter maniqueísta, com prognósticos dramáticos de divisão do país em raças e acusação de inconstitucionalidade das cotas. Contudo, o STF - Supremo Tribunal Federal julga, por unanimidade, a constitucionalidade das Ações afirmativas, liberando universidades públicas e instituições de ensino para adotarem as medidas em seus programas de graduação e de pós-graduação.

Após declaração de constitucionalidade das políticas públicas, que resultou na Lei das Cotas (Lei n. 12.711/2012), o que se observa são mudanças nos campi das universidades, com crescente número de alunos negros e negras. De antigos objetos de estudos, os jovens estudantes portam em si a riqueza da diversidade e atuam como sujeitos, eles próprios, por meio de participação em debates, salas de aula, produção de artigos, apresentação em congressos, e publicações. Ensaiam mudar o imaginário racista, presente na sociedade. "O racismo constitui todo um conjunto imaginário social que a todo momento é reforçado pelos meios de comunicação, pela indústria cultural e pelo sistema educacional” (Almeida, 2019, p. 65).

Por fim, o terceiro e último eixo abordará o tema sociedade civil versus justiça e democracia. Questiona ambos os conceitos, bem como o racismo epistêmico e o eurocentrismo, presentes na universidade. Estarão as instituições de ensino apenas cumprimento a Lei das Cotas ou abertas a novas epistemologias? Reflete acerca de possíveis ações da sociedade civil na luta contra o racismo, dentre elas a demanda pela inclusão de obras de intelectuais negros e negras nas grades curriculares das universidades e escolas. No campo midiático tensiona a comunicação tradicional com comunicações comunitárias, insumos para uma nova realidade.

$\mathrm{O}$ artigo trabalha com a perspectiva de que o equilíbrio social, econômico, político e cultural depende do amplo engajamento da sociedade civil pelos direitos humanos, reais e simbólicos, no combate ao racismo. Sem comprometimento e responsabilidade social, não há justiça social, nem democracia. As análises serão ancoradas metodologicamente em autores como Silvio Almeida (2019), Françoise Vergès (2005), Muniz Sodré (2014a, 2015), Michael Sandel (2012), Achille Mbembe (2018), Lélia Gonzalez (1982), Boaventura de Sousa Santos (2005), Gramsci (2007), Rancière (2018) e outros, a fim de 
compreender conceitos de justiça, democracia, e como a não superação do racismo interfere em uma sociedade supostamente democrática.

\section{Metodologia}

A comunicação enquanto campo da ciência, problematizada em "História das teorias da Comunicação" (Mattelart A. \& Mattelart M., 2005) pela amplitude, espalhamento e atravessamento por diversos outros campos do saber científico, encontra no método Sinóptico de caráter dialético-qualitativo, de Sodré (2014a, p. 19), práxis teórico-metodológica, capaz de abarcar o objeto e pressupostos a partir de trocas, tensionamentos e diálogos. Para Mattelart A. \& Mattelart M., 2005) diante da encruzilhada na qual se situa a comunicação, a teoria da comunicação também é afetada, considerando que ela própria produz clivagens (Mattelart \& Mattelart, 2005, p. 11).

A crítica dos autores (2005) é retomada por Sodré (2014a) acerca dos modelos sociológicos, econômicos e antropológicos, que não dão conta da complexidade do campo, e discute a possibilidade de uma ciência pós-disciplinar da comunicação, rejeitando, assim, pressupostos dominantes. Sodré (2014a, p. 92) aponta o que chama de "dispersão cognitiva", a dificuldade de estabelecer uma epistemologia para o campo da comunicação, impregnado pelo processo de financeirização do mundo.

Apesar de algumas tentativas isoladas, o campo permanece cientificamente tão ambíguo quanto no passado, em meio a milhares de estudos recortados sobre todo tipo de tema imaginável, se não diretamente relacionado à prática industrial da mídia ou do espetáculo diversificado, pelo menos permeável à colagem do par 'comunicação/informação' ou ajustável ao vago rótulo de 'estudos culturais'. Em si mesma, essa diversidade temática não é um problema, podendo mesmo ser considerada um índice de riqueza semiótica da comunicação. O problema está na falta de conexão das linhas de pesquisa, o que prejudica a coerência científica do campo e termina induzindo a dispersão cognitiva (Sodré, 2014a, p. 93-94).

O autor (2014a) observa que a causa pode estar na formação para o mercado e critica a maneira como os alunos participam deste aprendizado, de expectativa de satisfação. "Onde não há espírito republicano, o estudante é cliente, e não sujeito a se iniciar na plena cidadania" (Sodré, 2014a, p. 97). Mesmo em instituições públicas, considerando o mundo encampado pelo mercado, segundo Sodré (2014a, p. 98), há uma tentativa de rompimento do campo comunicacional em detrimento "do jornalismo como 'ciência' centralizadora, mas sem dizer com clareza o que se entende por ciência, fora dos chavões positivistas" (Sodré, 2014a, p. 98).

Mattelart e Mattelart (2005, p. 189) chamam a atenção para a derrocada da "ideologia racionalista do progressso", e ressaltam que a comunicação assume um lugar, se reconhecendo como parâmetro para a evolução da humanidade.

É certo que, como diz Georges Balandier, na voga que multiplica as pesquisas a incidir no cotidiano, o importante é o movimento dos espíritos 'que faz ressurgir o sujeito diante das estruturas e sistemas, a qualidade diante da quantidade, o vivido em face do instituído [Balandier, 1983]. As ciências do homem e da sociedade aproximaram-se, assim, do 'sujeito comum' (Mattelart \& Mattelart, 2005, p. 189).

E o que é esse sujeito comum? Embora os autores (2005) não tenham desenvolvido, preferindo falar da mídia e dos intelectuais afetados pelo positivismo, "por esse novo utilitarismo estimulador da pesquisa de ferramentas epistemológicas, que permitem a neutralidade das tensões via soluções técnicas" (Mattelart \& Mattelart, 2005, p. 190), Sodré (2014a) vai trazer a comunicação como organização do comum, ou da constituição do comum humano.

$\mathrm{Na}$ organização do comum, pode-se aplicar o método sinóptico, compreendido a partir de uma perspectiva sócio filosófica do autor (2014a), ou seja, vinculativa, em que estão expostos na arena de disputa conhecimentos diversos, tensionando entre si, portanto, permitindo ao pesquisador encontrar/escolher os pressupostos que deseja aplicar. Trata-se de 
explorar fragmentos diversos do conhecimento, rodear, abraçar, estudar, conhecer e reconhecer os objetos/sujeitos de estudos em todas as direções e sentidos. Dito de outro modo, no método sinóptico, o investigador assume a análise da mesma temática sobre diferentes pontos de vista.

Para este trabalho, a utilização do método sinóptico, de caráter dialético-qualitativo, visa a analisar o real histórico, frente a uma sociedade regida pela técnica e por ferramentas tecnológicas midiáticas, cada vez mais sofisticadas, cuja ideologia é a invisibilidade da diferença e o apagamento da história e da historicidade. A fim de compreender a relação entre justiça, democracia e sociedade, considerando o antigo sistema de governo escravocrata no Brasil, uma população negra de mais $56 \%$ e a naturalização midiática do racismo, este estudo, de perspectiva histórico-comunicacional-empírico, ampara-se em revisão bibliográfica, a partir de autores como Silvio Almeida (2019), Muniz Sodré (2014a, 2015, Françoise Vergès (2005), Michael Sandel (2012), Achille Mbembe (2018), Lélia Gonzalez (1982), Boaventura de Sousa Santos (2005), Gramsci (2007), Rancière (2018).

\section{Resultados e Discussão}

\subsection{Injustiça como padrão}

É célebre a frase atribuída ao filósofo inglês Thomas Hobbes, na obra $O$ Leviatã, de que o homem é o lobo do homem. Hobbes intercedia por uma liderança forte ou um contrato social que desse conta de reverter tal caráter, e evitasse que os homens se matassem mutuamente. Para Hobbes, o contrato social, com regras impostas pelo Rei, conduziria o homem à civilização. Frontalmente oposto a esse pensamento, Rousseau compreendia o homem como puro e bom por natureza, sendo corrompido pela sociedade ou pela propriedade privada. Defendia a luta pela igualdade para todos, assim como um contrato social, de modo a garantir uma democracia participativa. Essa disputa de pensamento social entre filósofos, um absolutista e o outro iluminista, leva a questionar, na contemporaneidade, não a natureza do homem, se bom ou mal, mas os contratos sociais. Pensados como controle do caráter violento do homem, ajustado ao longo dos séculos com outras considerações, o que se questiona é por que a sociedade, formada por humanos e por contratos, ainda não é constituída de justiça social?

A etimologia da palavra justiça, de acordo com dicionário de língua Portuguesa, vem do latim, justitia.ae., que significa correspondência, acordo com o que é justo; modo de entender e/ou de julgar o que é correto, dentre outras. Ao tomar posse na Presidência do Supremo Tribunal Federal (STF), em 22 de novembro de 2012, o ministro Joaquim Barbosa, primeiro homem negro a assumir a presidência do STF, declarou que a justiça por si só e para si não existe. Sua existência corresponde à forma e à medida em que os homens a desejam e a concebem. Ou seja, a justiça é humana, histórica e está imbricada com leis e cultura. "A justiça é elemento ínsito ao convívio social, daí porque a noção de justiça é indissociável da noção de igualdade, vale dizer a igualdade material de direitos, sejam eles direitos juridicamente estabelecidos ou direitos moralmente exigidos" (Barbosa, 2012, p. 49). Em seguida, o ministro esclarece que quando há associação entre justiça e igualdade "emerge, em sua inteireza, ao cidadão reivindicar o mais sagrado dentre os seus direitos, qual seja, o direito de ser tratado de forma igual, de receber igual consideração, a mesma que é conferida ao cidadão A ou ao cidadão C ou B” (Barbosa, 2012, p. 49).

Vendo a justiça sob esse prisma, e considerando a história do Brasil Colônia e Império de escravização de povos africanos, seguida da prática de violência e morte, torna-se inegável apontar que o país, já na origem, é marcado pela injustiça. Foram mais de 350 anos de escravização. No período entre 1550-1886, de um total de cerca de 11 milhões de africanos deportados nas Américas, 44\% vieram para o Brasil. Os dados são de Luiz Felipe de Alencastro, para quem o Brasil foi o país americano que mais praticou a escravidão. Alencastro (2014, p.149-150) observa que os africanos arrancados de seus territórios, se incorporaram aos engenhos e as fazendas, passando a viver sob o estatuto da sociedade luso-brasileira. "Perecendo como pessoas ao cair cativo no Continente negro, o africano converte-se em mercadoria - em 'peça' marcada a 
ferro e tributada pela Coroa no porto de trato - para renascer como fator de produção implantado na América portuguesa" (Alencastro, 2014, p. 149-150).

O reverso da justiça se materializa já no início do tráfico e da captura do africano, que sofre dupla morte social, a saída da terra natal e a condição de não sujeito. Ideologicamente racializado, o negro, que não existia enquanto tal, "é constantemente produzido. Produzi-lo é gerar um vínculo social de sujeição e um corpo de extração, isto é, um corpo inteiramente exposto à vontade de um senhor e do qual nos esforçamos para obter o máximo de rendimento" (Mbembe, 2018, p. 42). Os que conseguiam sobreviver à travessia marítimas eram descarregados nos portos e expostos em mercados de escravos para serem vendidos. Dali em diante, a história é de violência e barbárie, com trabalhos forçados em condições precárias, acoites, castigos físicos, estupros e mortes. Compreendidos como coisas, eles não faziam parte das leis. Emilia Viotti da Costa ressalta que, embora na Carta Constitucional de 1824, tenha sido transcrito, na integra, um artigo sobre a Declaração dos Direitos do Homem e do Cidadão da original francesa de 1789, na qual se afirmava a liberdade como um direito inalienável do homem, o país manteve quase a metade da população brasileira escravizada. "A constituição ignorou os escravos. Sequer reconheceria sua existência. A eles não se aplicavam as garantias constitucionais" (Costa, 2001, p. 19).

Estava posta a contradição. De um lado, uma Constituição de caráter liberal, do outro, um sistema de governo fundado no cativeiro, evidenciando uma condenação "em termos morais, religiosos e econômicos" (Costa, 2001, p. 19). Para Costa (2001, p. 19) essa Constituição teria sido um passo para a formação de consciência. Mas, usando expressão de Gramsci, teria sido uma consciência pelo alto. Ou seja, como afirma Muniz Sodré, a ideia era libertar os brancos de um sistema anacrônico.

O liberalismo que levou segmentos da elite monarquista a reivindicar a abolição da escravatura não estava comprometido com a realidade social e humana da maioria populacional, que era constituída pelos africanos e seus descendentes, e sim com a adequação das ideias nacionais ao ideário culto da Europa (Sodré, 2015, p. 90).

De todo modo, após a Constituição de 1824, a convivência entre os princípios liberais e o sistema de governo escravista prosseguiu ainda por mais de meio século. Se na Constituição não havia referência ao escravizado, a despeito da realidade empírica, o tema estava na roda. "O debate sobre a natureza jurídica do escravo versa necessariamente sobre a controvérsia se aquele ser humano, à luz do direito, deveria ser regido pelo regime jurídico das coisas ou das pessoas" (Campello, 2013, s/p.). Apesar do contexto, lutar para ser sujeito de direito, ser cidadão pleno se mantém na esfera do debate.

Um universo de leis controversas é propício a variados tipos de injustiça e de sofrimento. "O submundo a que eram submetidos os africanos escravizados desnudava mais uma incoerência no universo do discurso de caráter abstrato, da retórica e das práticas cotidianas" (Martins, 2015, p. 80). Um exemplo foi a lei assinada em 1831 pelo governo brasileiro, proibindo o tráfico de pessoas negros, por pressão da Inglaterra, cujo descumprimento previa severas penas aos traficantes. Aqueles tornados prisioneiros rumo ao Brasil, a partir daquela data eram considerados livres pela Lei. A medida não só foi desrespeitada, como ainda gerou a expressão "para inglês ver", indicativo de enganação em voga até os dias presentes. Mesmo diante da proibição oficial do tráfico, no período de 1831 a 1850, foi intensificado sob força, a entrada de africanos no país, e “mais de meio milhão de escravos foram introduzidos no País, em total desrespeito a lei de 1831" (Costa, 2001, p. 27).

Nesse contexto, a Corte luso-brasileira tornou real a famosa frase de Hobbes, dita acima e, seja jurídica ou historicamente, a Corte tem uma dívida com o Brasil. Parafraseando Aimé Césaire (2004), uma sociedade que escravizou homens, mulheres e crianças, por quase quatro séculos, e é incapaz de resolver as consequências desse ato, é uma sociedade enferma. Uma sociedade que aboliu a escravidão com apenas dois artigos e sem qualquer reparação aos séculos de crime e de violência contra a população africana deportada para o Brasil, e os afrodescendentes é uma sociedade moribunda. Uma sociedade, cujos princípios republicanos não são cumpridos é uma sociedade decadente. Foram nessas condições que os 
escravizados e seus descendentes viveram séculos de tratamento discriminado, de perda de ontologia física e psicológica e se viram tornados objeto sem alma, discurso da igreja para apaziguar a consciência dos escravocratas. Uma injustiça combinada num tripé governo-igreja-sociedade que inculcou a inumanidade justo daqueles que construíam o país.

A distância entre o conceito de justiça, declarado pelo então presidente do STF e o mundo da vida dos afrodescendentes brasileiros (justiça e ideal de justiça) traz resquícios de um período abominável, que a sociedade deve respostas. Novamente, aqui, está estampada a incoerência jurídica entre uma sociedade democrática e uma sociedade real. Sodré (2015) apresenta a "forma social” subsistente do que chama de “"comunidade íntima' das classes dirigentes - o estamento patrimonial, que interioriza o tempo histórico, criando e recriando um passado e um futuro afins a um projeto de grupo. O patrimonialismo brasileiro é, assim, a reinterpretação cultural de um traço civilizatório" (Sodré, 2015, p. 141). Diz que o patrimonialismo concilia "uma aparência moderna (jurídico-racional) de nação com a tradição de vassalagem do povo pelo Estado, sempre tutelado por um estamento que se autoperpetua no poder" (Sodré, 2015, p. 141) até os dias presentes.

$\mathrm{O}$ resultado dessa combinação de poder é a permanência no interior da sociedade de um racismo profundo de diferentes dimensões. Trata-se, para Silvio Almeida, do racismo estrutural, presente em todos os segmentos sociais e mesmo na força da ordem pública. De acordo com o autor (2019), o racismo é decorrente do modo com que se constituem as relações políticas, econômicas, jurídicas e mesmo familiares. "Comportamentos individuais e processos institucionais são derivados de uma sociedade cujo racismo é regra e não exceção" (Almeida, 2019, p. 50). Já para Sodré, não se trata de estrutura, mas de forma social escravista. O racismo no cotidiano, mesmo aquele difícil de identificar, é resultado de uma mentalidade ideologicamente construída e profundamente escravocrata. Ou seja, embora não verbalizado, o racismo na sociedade reforça um modelo, compreendido por Sodré (2015) como “forma social”, que resulta em injustiça histórica, naturalizada pela mídia e pelo conjunto da sociedade civil. A compreensão dessas raízes torna ainda mais urgente a necessidade de respostas contundentes e ações conjuntas de toda a sociedade no combate ao racismo.

\subsection{Ações Afirmativas e rejeição às políticas públicas}

Para falar de Ações Afirmativas é necessário contextualizar historicamente. Na contemporaneidade, muitos teóricos se debruçam sobre a temática da escravidão e suas consequências profundas. Em Crítica da razão negra, Achille Mbembe (2018, p. 121) vai dizer que a palavra negro, assim como raça não existem. Ambas são resultados de construções discursivas pelo ocidente, como a invenção de elementos de fabulação pelo discurso europeu no modo de pensar, classificar e imaginar mundos distantes, apresentando fatos como reais, certos e exatos ainda que inventados. Observa que uma das construções discursivas é de que a África não tem história. Outra é mostrar o africano como criança idiota. "Essa idiotia seria consequência de um defeito congênito da raça negra. A colonização seria uma forma de assistência, de educação e de tratamento moral dessa idiotia além de um antídoto para o espírito de brutalidade e para funcionamento anárquico das 'tribos nativas"” (Mbembe, 2018, p. 121). Tal modo de pensar servia como pano de fundo para aliviar as consciências mais suscetíveis e anular qualquer possibilidade de aliança e reações contra o colonialismo.

Depois de uma importante campanha abolicionista no Brasil, liderada, entre outros, por homens negros, livres, o fim da escravidão não foi capaz de acabar com a violência, e ainda aprofundou o racismo. Diante do vazio do ato da abolição, sem qualquer responsabilidade política por parte do Estado, novas frentes de lutas tornam-se inevitáveis. Tanto no campo empírico como teórico surgem denúncias e proposições, a exemplo de autores da pós-colonialidade. Nas palavras de Françoise Vergès (2005) a pós-colonialidade trabalha na perspectiva de desconstruir a leitura da história, evidenciando que a escravidão não se deu apenas em um período histórico determinado, mas opera como uma estrutura de organização das relações humanas, atuando nas relações sociais, seja no imaginário, seja nas relações com a terra, no trabalho, no tempo e na existência. "[A teoria] analisa as novas formas de brutalidade e de violência na nova etapa de globalização, e propõe práticas de solidariedade 
com os grupos e povos submissos a tais violências"1 (Vergès, 2005, p. 80).

No Brasil, o Movimento da Eugenia atuou fortemente no início do século XX, liderado por intelectuais brancos, com destaque para o ícone da literatura infantojuvenil, o poeta e escritor Monteiro Lobato, que não escondia o racismo, como na obra de ficção "O Presidente Negro" (1926), cujo enredo envolvia laboratório de embranquecimento da população, disputa eleitoral e assassinato do adversário negro. Seja na literatura, nos livros didáticos, ou em atos voluntários, os efeitos da violência racista reverberam. Mas não sem reação. A luta data do início da deportação dos africanos e segue, após a abolição, reivindicando a liberdade efetiva, entra no século XX e se prolonga pelo XXI, contra a prática do racismo que "desagrega a sociedade e impede seu potencial humano de se manifestar plenamente. E o Brasil precisa de coesão do seu povo para ter equilíbrio social e prosperidade sustentável" (CUTI, 2010, p. 6).

É nesse cenário histórico de opressão, que emergem as Ações Afirmativas no Brasil. Estas são gestadas a partir de movimentos regionais e nacionais de reivindicações, como combate ao racismo, educação e reconhecimento, e acolhidas na Conferência de Durban, na África do Sul. Delegações brasileiras presentes na III Conferência Mundial contra o Racismo, a Discriminação Racial, a Xenofobia e Formas Correlatas, promovida pela ONU, em Durban, em 2001, testemunharam o resultado de suas lutas, com declaração do governo brasileiro de que o país implantaria medidas de reparação. Em seguida, deu-se início a implantação das políticas públicas de caráter afirmativo, seguida pelo surgimento de novos combates, provocando o ressurgimento daquilo que Pollak (1989) chama de "memórias subterrâneas", ou seja, reminiscências antigas de opressão e de violência, sofridas por séculos.

A implantação de políticas públicas, sobretudo de cotas raciais, uma das modalidades das Ações Afirmativas, provocou forte reação. Os argumentos viraram jogos de imposição de verdades. Os opositores tentavam silenciar a real causa da proposição, desviando o sentido e retirando do tema a importância histórica. As cotas foram demonizadas pela mídia, com discursos maniqueístas, de contrários e favoráveis, até serem julgadas constitucionais pelo Supremo Tribunal Federal (STF), por unanimidade, em 2012. Até então, o debate era da ordem da opinião. Surgem questionamentos sobre a dificuldade de definição fenotípica em uma sociedade de larga paleta de cores. Mas também suscitam reações, como o mérito individual, intocável, até o advento das Ações Afirmativas. Problematizado, o mérito é desvendado e aparece como historicamente tem sido representado, muito mais um privilégio de acesso à universidade pública do que um sistema de avaliação infalível. Na realidade, o mérito é uma violência contra minorias, o disfarce inapercebido do colonialismo, mas também não sem reação. As cotas raciais, serviram, no limite, para colocar o tema das relações raciais na mesa de debate. Com isso, o país saiu de uma suposta democracia racial para uma demonstração raivosa contra a população negra.

E logo surgiram as reatualizações do discurso, do século XIX para o XXI, por meio da utilização de termos como "medo da divisão do país em raças", "abriram as portas do ódio racial”, ou ainda pela escolha, em nome próprio, do que seria bom para o outro. Além disso, a narrativa midiática, utilizada em jornais como Folha de S. Paulo e $O$ Globo, praticou exnominação, termo empregado por Rolland Barthes, que seria o esvaziamento do sujeito pelo discurso, repetindo o século XIX. Os jornais não pronunciavam o nome do candidato ou do estudante negro. Este, midiaticamente ceifado de sua subjetividade, passou a ser cotista. É narrado na imprensa apenas como negro, perdendo o status de estudante. Várias são as matérias que praticam a exnominação do afro-brasileiro: "reserva de vagas para negros", "o cotista negro...", "a cota para negro", em oposição a "reserva de vaga para aluno da rede pública", "estudante pobre, cotista...", "a cota para aluno da rede pública," etc. Estranho é que as cotas sociais não faziam parte da luta original. Entraram no bojo das reivindicações de outros movimentos, sendo aceitas pela mídia, com alguma contestação, mas muito mais facilmente do que as cotas raciais.

${ }^{1}$ Trad. Livre: "Elle analyse des nouvelles formes de brutalité et de violence à l'oeuvre dans la nouvelle étape de globalisation et propose des pratiques de solidarité avec les groupes et les peuples soumis à ces violence." (Vergès, 2005, p. 80). 
Foram muitos os argumentos contrários, dentre eles aqueles que diziam que haveria evasão escolar, que o aluno era despreparado para ingressar na universidade ou ainda que iria baixar o nível do ensino. Após mais de quinze anos de prática e quase dez anos de legalidade das políticas públicas, pelo STF, o prognóstico midiático não se confirmou. Pelo contrário, exalunos que saíram das graduações ingressaram, também como estudantes cotistas, em programas de Pós-Graduação de diversas universidades do país e estão brilhando com seus debates, suas culturas, criticando a grade eurocêntrica e trazendo novas epistemologias. Esses intelectuais orgânicos, para usar termos de Gramsci, confirmam o potencial das Ações Afirmativas de promover o contra discurso ao discurso hegemônico. O que se evidencia é que o sistema de cotas resulta em política de enfrentamento, de reivindicação e de compreensão de direitos jurídicos, reais e simbólicos. Podem-se afirmar, nas palavras de Sodré (2014a), que as Ações Afirmativas e as cotas raciais são lutas por direitos à "isonomia" (igualdade de direitos perante a lei), à "isotopia" (igualdade de lugar), è à "isogoria" (igualdade de discurso).

Tem ainda o princípio da diversidade, trazido por Sandel (2012), considerando que este se justifica em nome do bem comum, ou seja, o bem comum da própria faculdade e também da sociedade em geral. "Primeiro, defende que um corpo estudantil, com diversidade racial permite que os estudantes aprendam mais entre si do que se todos tivessem antecedentes semelhantes" (Sandel, 2012, p. 213). O autor (2012) argumenta que se fosse trazido para a instituição de ensino os mesmos temas e proposições de uma única área do conhecimento do país, isso enfraqueceria as perspectivas intelectuais e culturais do ensino. Em seguida, ressalta que "o argumento da diversidade considera que as minorias deveriam assumir posições de liderança na vida pública e profissional, porque isso viria ao encontro do propósito cívico da universidade e contribuiria para o bem comum" (Sandel, 2012, p. 213).

O ingresso na universidade por meio de cotas, afirma Martins (2015), representa não apenas explorar o potencial do aluno enquanto sujeito cognoscente, mas impõe a presença de um limite, que existe, está ali, constante e que exige do indivíduo refletir sobre sua própria condição de homem ou de mulher, negro/a, discriminado/a em uma sociedade racista. Além disso, possibilita ao estudante fazer escolhas conscientes, como o tema de pesquisa que desejar, tomar atitudes, repensar a vida acadêmica na coexistência com seus colegas, professores, instituição, cidade e trazer contribuições para o debate. Dessa tensão e do deslocamento social, a perspectiva é de surgimento de um novo sujeito, pleno de direito e potencialmente "autorizado a assumir um lugar de fala, não um lugar concedido socialmente, mas um lugar conscientemente escolhido e legitimado" (Martins, 2015, p. 284). A autora (2015) acrescenta que essa dinâmica tem forte potencial para reverter a prática de exnominação a partir do enfrentamento do racismo, assim como pela participação enquanto intelectuais orgânicos no fortalecimento da sociedade civil, com consciência política e responsabilidade social.

Trata-se do exercício de cidadania para todos e não apenas para alguns, os mesmos. As Ações Afirmativas devolvem à sociedade o vigor de novos intelectuais que contribuem para o debate, produzem novos conhecimentos, seja em publicações de artigos, seja em participação em congressos. São os intelectuais orgânicos que rejeitam os gabinetes fechados e preferem interferir no social. É o caso da publicação: “'O Brasil não pode parar': racismo e desigualdade social na campanha publicitária do governo Bolsonaro" (Sanches, Moisés, Souza, 2020). No artigo, três jovens, dois doutorandos e um mestrando, trabalham com o conceito de representação social para analisar a peça (vídeo) publicitária e mostrar a incoerência entre o discurso e a imagem (o áudio se reportava a profissionais liberais como engenheiros, advogados, arquitetos, etc., enquanto mostrava imagens de homens e mulheres trabalhadores, pobres, todos negros).

Em diálogo com Sílvio Almeida (2019), os autores (2020) ressaltam: “'O Brasil não pode parar’ endereçou à população brasileira um conjunto de códigos sociais marcadamente racistas, cujas peças do quebra-cabeça apontam para a existência do racismo estrutural" (Sanches et al., 2020, p. 98-99). Mais a frente, chamam a atenção para a violência que insiste em manter o país longe dos parâmetros de justiça social. "No século XXI, as reencenações coloniais do racismo cotidiano revelam que as representações das pessoas negras no Brasil ainda são alimentadas pelo estereótipo da subalternidade e 
subserviência, reiterando códigos, linguagens e imagens, que marcam as divisões sociais e a desigualdade racial" (Sanches $e t$ al., 2020, p. 105).

A fala de denúncia dos jovens pesquisadores negros estava submersa no medo das elites brancas brasileira, quando lá no início do XXI negavam, veementemente, as cotas raciais. Essa elite branca temia não ser mais porta-voz da verdade, não aceitava e ainda não aceita a dialética a partir de dados concretos, preferindo temas hipotéticos e discursos flácidos. Contudo, as cotas raciais reivindicam um tempo histórico e trazem outra conotação: a do sujeito singular. Ou seja, com as cotas o negro deixa de ser objeto de estudo e se torna sujeito. "O negro, que tinha um lugar, aparece agora como um lugar, ele próprio" (Santos, 2010, p. 56). A explicação filosófica do autor aponta que "o negro deixou de ser negro em si para se tornar negro para si" (Santos, 2010, p. 56). Esse deslocamento apontado por Joel Rufino dos Santos era o temor da elite branca com as cotas e isso provocou, nas palavras de Sodré (2015), um certo mal-estar civilizatório.

\subsection{Sociedade civil versus justiça e democracia}

Embora os movimentos negros tenham lutado sempre contra a opressão e o racismo nas mais diversas formas de manifestações e exercido pressões políticas, o fato é que não foram suficientes para mudar atitudes cotidianas racistas no país. Uma das explicações encontra-se na formação política do Brasil, historicamente contraditória. Desde o século XIX, em meio a Campanha Abolicionista, Alfredo Bosi observa que as contradições atravessavam as relações, não importando se a pessoa era monarquista, republicana ou liberal, havendo de tudo no país, como políticos que desejavam a República, mas não defendiam nem os ideais republicanos, nem os democráticos. "Até meados do século, o discurso, ou o silêncio, de todos foi cúmplice do tráfico e da escravidão" (Bosi, 1988, p. 21).

A palavra República vem do latim res publica, que significa coisa pública, governo de muitos, coletivo. Já democracia vem do grego e significa demos, povo; kratía, poder, ou seja, poder do povo, força, forma de governo em que a soberania é exercida pelo povo. Contudo, a República brasileira já começou invertendo ambos os conceitos, considerando que a própria proclamação pegou a todos de surpresa, inclusive Aristides Lobo, o propagandista do novo sistema de governo. José Murilo de Carvalho narra declaração de Lobo para quem "o povo, que pelo ideário republicano deveria ter sido protagonista dos acontecimentos, assistira a tudo bestializado, sem compreender o que se passava, julgando ver talvez, uma parada militar" (Carvalho, 2012, p.9). A bestialidade do início da primeira República estava justamente em negar o princípio da própria existência, o povo, sendo fundada por meio de um golpe. Além disso, diz Bosi (1988), os jogos de interesses eram compatíveis com a liberdade entre integrantes da oligarquia. Ou seja, "descartava as conotações inoportunas, isto é, as exigências abstratas do liberalismo europeu que não se coadunassem com as particularidades da nova nação.” (Bosi, 1988, p. 21).

Assim nasceu a República, atendendo a interesses de fazendeiros, políticos, elite. Nessa arena de apegos políticos e econômicos, a imprensa se industrializa, deixando de ser artesanal e, desse modo, pouco a pouco a sociedade civil vai se formando e se fortalecendo ao longo do século XX. Nesse início e meados do século surgiram jornais da imprensa negra, clubes, associações, escolas, movimentos diversos, como a Frente Negra Brasileira, o Movimento Negro Unificado, o Teatro Experimental do Negro, alguns mais conservadores, outros de inspiração marxista. Mas um novo golpe atingiu a sociedade civil, limitando atividades. "Dizemos que as elites intelectuais negras foram desarticuladas pelo golpe de 64. De fato. O autoexílio de Abdias Nascimento, enquanto figura das mais representativas, senão a mais, de todo um trabalho desenvolvido na fase anterior confirma o que dizemos" (Lélia, 1982, p. 30).

Essas articulações negras, como jornais, associações, clubes e escolas faziam parte da sociedade civil orgânica, cujo objetivo era interferir no modelo societário racista, com denúncias, e alternativas culturais. Mas eram incipientes. Para Coutinho (2007, p.128), as organizações do início do século não tinham força para enfrentar o Estado, em um combate contra hegemônico, considerando que de um lado o Estado possui os aparelhos repressores e o aparato político-militar; do outro, "os 
portadores da sociedade civil são o que Gramsci chama de 'aparelhos privados de hegemonia', ou seja, organismos sociais coletivos voluntários e relativamente autônomos em face da sociedade política" (Coutinho, 2007, p. 128-129).

Nas sociedades contemporâneas, dominadas pelo mercado, Boaventura de Souza Santos observa que é preciso dar atenção igual às dimensões social, política e cultural. Com a globalização, diz o autor (2005), o que ocorre é um vasto campo de conflito entre grupos sociais. "Estados e interesses hegemônicos, por um lado, e grupos sociais, Estados e interesses subalternos, por outro; e mesmo no interior do campo hegemônico há divisões mais ou menos significativas" (Souza Santos, 2005, p. 27). Ainda assim, aponta um consenso entre grupos hegemônicos. Explica que esse consenso entre os membros mais influentes "confere à globalização características dominantes como também legitima estas últimas como as únicas possíveis ou as únicas adequadas" (Souza Santos, 2005, p. 27). O autor fala do consenso neoliberal, ou Consenso de Wastington, que regula a economia mundial e interfere no papel do Estado na economia.

Diante do neoliberalismo, cenário de dominação, e considerando uma sociedade profundamente racista, marcada pelas desigualdades raciais e socioeconômicas históricas, é possível viver uma democracia? Na opinião de Rancière (2014), a palavra democracia não representa precisamente nem uma forma de sociedade, nem uma forma de governo. $\mathrm{O}$ autor recorre ao imaginário de uma pintura fantasiosa para comparar as sociedades democráticas, afirmando que seja no presente ou no passado, tais sociedades, ditas democráticas, são organizadas pelo que chama de jogo das oligarquias. "E não existe governo democrático propriamente dito. Os governos se exercem sempre da minoria sobre a maioria. Portanto, o 'poder-do-povo' é necessariamente heterotópico à sociedade não igualitária, assim como ao governo oligárquico” (Rancière, 2014, p. 68).

Como a sociedade civil pode interferir para transformar essa realidade? Ora, no caso de violência provocada por racismo, Sodré (2020) afirma que a manifestação da sociedade civil depende do grau de empatia, explicada como identificação com o outro, compaixão, sentimento de solidariedade. O autor (2020) afirma que esse sentimento geralmente não acontece quando as pessoas são pobres, negras ou africanas. Referindo-se a violência da polícia americana, no caso de George Floyd, cuja repercussão foi mundial, Sodré (2020) diz que a explicação está na sociedade civil da República Norte Americana, que é forte e importante. "A violência contra um homem negro nos EUA é globalmente percebida como violência contra a sociedade civil americana, que é um baluarte suposto de garantias democráticas no mundo" (Sodré, 2020).

Em seguida, o autor (2020) observa que a reação social à violência, não se trata de empatia com George Floyd, com o sujeito em si, mas com um integrante de uma sociedade privilegiada, ou mitificada, a fim de garantir a estabilidade social Norte Americana. Vale observar que a população negra nos Estados Unidos é de cerca de 13\%, enquanto no Brasil, o conjunto de negros e pardos, conforme denominação do IBGE, supera a maioria da população brasileira, ou seja, 56,10\% e nem assim a violência causa comoção social. O discurso da mídia tradicional, um dos organismos da sociedade civil, já convida a opinião publica a não se solidarizar, porque naturaliza a violência como apenas mais uma morte. É usual noticiar-se mais um caso de violência, muitas vezes a vítima já como suspeita e, geralmente, sem família, sem amigos, sem subjetividade.

A expectativa de mudança da frieza discursiva midiática concentra-se na comunicação comunitária, que tensiona esse modelo tradicional verticalizado, por meio de um trabalho orgânico, envolvendo efetivamente a comunidade e a comunicação, que atua enquanto ponte entre a população e os veículos comunitários. A despeito do conceito de comunidade ser questionado em países europeus, Raquel Paiva ressalta que a reinterpretação de comunidade, “[...] para os países do hemisfério sul, sugere uma ordem alternativa de existência, pensamento e postulado, capaz de engendrar novos e novíssimos formatos de existência" (Paiva, 2007, p. 13). Trata-se de uma comunidade compreendida como "o retorno de uma temática que se deixa ver de forma explícita em construções teóricas ou, de forma oblíqua, em intervenções práticas na vida social” (Sodré, 2007, p. 7). O que se observa é que as cotas raciais também vêm interferindo na comunicação hegemônica, quando denuncia a prática racista e reivindica maior representação.

Outra esfera da sociedade civil, a universidade pública, tem potencial de transformar o paradigma, com intervenção 
social a partir do seu interior. Tradicionalmente de grade eurocêntrica, com foco em escolas do pensamento europeu, a universidade vive o dilema entre o modelo ocidental e as possibilidades de inclusão de novos saberes. Os novos estudantes cotistas rejeitam o racismo epistêmico e lutam pela adoção de obras de intelectuais negros. Sociologicamente, estão em diálogo com Boaventura e com as Epistemologias do Sul, que "[...] se referem à produção e validação dos conhecimentos ancorados nas experiências de resistência de todos os grupos sociais que sistematicamente têm sofrido a injustiça, a opressão e a destruição causada pelo capitalismo, o colonialismo e o patriarcado" (Souza Santos, 2018, p. 299). À luz das epistemologias do Sul, os novos sujeitos têm a possibilidade de pensar o mundo a partir de suas próprias experiências. Ou seja, a realidade não permite mais eufemismos.

Nesse sentido, a universidade tem dois caminhos. Primeiro, insistir numa ciência como verdade única, deixando escapar que ao contrário do que parece, não está praticando a diversidade, está cumprindo um ato formal, a implantação da lei, como a Lei das Cotas. Essa opção, revela a não preocupação com o sujeito em si, mas com o imaginário de manutenção de lugar, um incluir sem incluir. O segundo caminho, leva à uma posição contrária aquela supostamente adotada pela sociedade americana que prima pela estabilidade, como diz Sodré (2020), sem perceber o humano, porque deixará fluir a potência e o vigor da coexistência de saberes, mesclando uma grade curricular que também contemple os africanos, descendentes, indígenas e outras minorias. Essa escolha, caso ocorra, permitirá abertura, acolhimento da diversidade, de fato, e comprometimento com a construção de um novo socius, além do próprio aprendizado.

\section{Considerações Finais}

O debate em torno dos três temas apresentados evidencia a necessidade do enfrentamento da desigualdade e da violência contra a população negra, dentre outras minorias. Sem isso, qualquer proposta de justiça social é pura retórica. Mudar a estrutura racista do país, enraizada na prática cotidiana e no imaginário social, como diz Almeida (2019), exige um esforço da sociedade civil, combinado com vontade política do Estado e pressão das bases. Dito de outro modo, não é possível viver uma democracia sem justiça social de fato. Não uma justiça formal, mas aquela que combine realidade concreta de direitos materiais e simbólicos. Os questionamentos acerca da desigualdade no país e da injustiça que representa não terão respostas, caso a sociedade siga com o foco na lucratividade, no mercado, no não humano, ou na humanidade supérflua, nomeada por Mbembe (2018), que é aquela relegada ao abandono e indiferença, por não possuir qualquer utilidade para o capital.

Pensar nos conceitos de justiça, de democracia e no real histórico brasileiro, leva a supor que o sentido de pertencimento do afro-brasileiro parece estar sempre derrapando, haja vista a reação midiática, com discursos negativos e violentos, como se deu no caso das Ações Afirmativas, diante da possibilidade de deslocamento de lugar do/a jovem negro/a. Isso revela um hiato na "força" e no "poder do povo" e no direito à cidadania, frente à democracia. A mesma fragilidade perpassa o conceito de justiça, considerando a natureza definidora de inseparabilidade entre justiça e igualdade material de direitos, sejam jurídicos ou direitos morais exigidos, como afirma Barbosa (2012), o afrodescendente e a realidade.

Se para alguns pensadores a justiça social e a democracia tal qual teorizada, não existem, precisam ser reinventadas. Ou seja, é inegável que a sociedade, feita de contratos e de homens, não funciona ou está em crise. Parece evidente que os modelos hegemonicamente adotados falharam. A reinvenção do ethos humano pode estar na reunião de alguns princípios capazes de transformar as relações pela diversidade, pela solidariedade ou, ainda, a partir da compaixão, como diz Sodré (2020), e de estar aberto ao outro. Uma condição de possibilidade são os sujeitos das Ações afirmativas e cotas raciais que vem lutando pela ampliação de vozes, junto às universidades públicas, numa dialética capaz de mexer com as certezas da sociedade civil em busca de um novo sujeito social. Trata-se de um agir político pela cultura.

Finalmente, se a grandeza da universidade está na diversidade de ensinamentos científicos, como argumenta Sandel (2012), a potência de coexistência com outras culturas atravessa a diversidade da população, a incorporação de novas 
epistemologias, trocas e dialética. Portanto, as Ações Afirmativas e as cotas raciais trazem esse potencial e abrem o debate, colocando em pauta as discussões acerca da justiça e da democracia diante do racismo. As Ações Afirmativas são um ato político e põem em xeque o papel da sociedade civil, indiferente à violência dessa prática, da mentalidade escravocrata da sociedade brasileira, que mata diariamente o sujeito simbólico antes da morte física. Os novos intelectuais orgânicos demandam uma sociedade combativa, aberta e solidária, cujas subjetividades sejam respeitadas. Os afro-brasileiros estão ancorados na força do debate, da solidariedade entre si, na conscientização racial e dispostos a reescrever a história.

\section{Referências}

Alencastro, L. F. de. (2014). O trato dos viventes: formação do Brasil no Atlântico Sul (8a ed.). Companhia das Letras.

Alencastro, L. F. de. (2010). Parecer sobre a Arguição de Descumprimento de Preceito Fundamental, ADPF/186, apresentada ao Supremo Tribunal Federal. 2012. Recuperado de https://www.adusp.org.br/files/GTs/etnia/parecer.pdf.

Almeida, S. (2019). Racismo estrutural. Sueli Carneiro; Pólen.

Barbosa, J. (2012). Posse na presidência do Supremo Tribunal Federal: Ministro Joaquim Benedito Barbosa Gomes, Presidente; Ministro Ricardo Lewandowsky. Supremo Tribunal Federal - Biblioteca Ministro Victor Nunes Leal. 16-17. Recuperado 14 abr., 2021 de http://www.stf.jus.br/arquivo/cms/publicacaoPublicacaoInstitucionalPossePresidencial/anexo/Plaqueta_Possepresidencial_JoaquimBarbosa_NOVACAPA.pdf

Bosi, A. (1988). A escravidão entre dois liberalismos. Estudos av., 2 (3), 4-39. https://www.revistas.usp.br/eav/article/view/8495

Campello, A. E. B. B. (2013). A escravidão no Império do Brasil: Perspectivas Jurídicas. Sinprofaz, https://www.sinprofaz.org.br/artigos/a-escravidao-noimperio-do-brasil-perspectivas-juridicas/.

Carvalho, J. M. de. (2012). Os bestializados: o Rio de Janeiro e a República que não foi (3a ed.). Companhia das Letras.

Césaire, A. (2004). Discours Sur le Colonialisme (1 ${ }^{\mathrm{a}}$ ed. 1955). Paris: Présence Africaine.

Chandler, D.; Munday, R. (2011). A Dictionary of Media and Communication. Subject: Media studies. Current Version. https://www.oxfordreference.com/search?source=\%2F10.1093\%2Facref\%2F9780199568758.001.0001\%2Facref-9780199568758\&q=exnomination.

Costa, E. V. da. (2001). A Abolição (7a ed.). Global.

Coutinho, C. N. (2007). Gramsci: Um estudo sobre seu pensamento político (3a ed.). Ed. Civilização Brasileira.

Cuti. (2010). Quem tem medo da palavra negro. Mazza Ed.

Dicio - Dicionário online de Português. https://www.dicio.com.br/justica/.

Gonzales, L. (1982). Lugar de Negro / Lélia Gonzales e Carlos Hasenbalg. Marco Zero.

Martins, Z. (2015). Cotas raciais: Para reatualizar o discurso da imprensa e inverter a abolição da escravatura. Tese de doutorado apresentada a Escola de Comunicação da Universidade Federal do Rio de Janeiro, Rio de Janeiro, RJ, Brasil.

Mattelart, A. \& Mattelart, M. (2005). História das teorias da Comunicação. Ed. Loyola.

Mbembe, A. (2018). Crítica da razão negra. n-1.

Michaelis - Dicionário Brasileiro de Língua Portuguesa. https://michaelis.uol.com.br/moderno-portugues/busca/portugues-brasileiro/republica.

Paiva, R. (Org.). (2007). Apresentação. O retorno da comunidade: os novos caminhos do social Mauad X.

Pollak, M. (1989). Memória, Esquecimento e Silêncio. Estudos Históricos. 3-15. http://www.uel.br/cch/cdph/arqtxt/Memoria_esquecimento_silencio.pdf

Rancière, J. (2014). O ódio à democracia. Boitempo.

Sanches, J. C.; Moisés, R. J.; Souza, R. P. da C. (2020). “O Brasil não pode parar”: racismo e desigualdade social na campanha publicitária do governo Bolsonaro. Revista Brasileira de História da Mídia, 9 (2), 95-113.

Sandel, M. J. (2012). Justiça: o que é fazer a coisa certa Civilização Brasileira.

Santos, J. R. dos. (2010). A Metamorfose do Negro. In: Santos, J. R. dos; Lopes, N; Costa, H. Nação Quilombo. Rio de Janeiro: ND Comunicação.

Sodré, M. (2015). Claros e Escuros: Identidade, povo, mídia e cotas no Brasil (3a ed.). Ed. Vozes.

Sodré, M. (2014a). A Ciência do Comum: notas para o método comunicacional. Ed. Vozes.

Sodré, M. (2014b). Joaquim Barbosa é um lugar. Observatório da Imprensa. Observatório da Imprensa. (807), s/p. http://www.observatoriodaimprensa.com.br/jornal-de-debates/_ed807_joaquim_barbosa_e_um_lugar/. 
Research, Society and Development, v. 10, n. 16, e466101623222, 2021

(CC BY 4.0) | ISSN 2525-3409 | DOI: http://dx.doi.org/10.33448/rsd-v10i16.23222

Sodré, M. (2007). Prefácio. O retorno da comunidade: os novos caminhos do social Mauad X.

Sodré, M. (2020). Cabral Muniz Sodré Reflexões. Rio de Janeiro, 05 set. $2020 . \quad$ Instagram: @cabralmunizsodre. https://www.instagram.com/tv/CEw0yO9J7GH/?igshid=ltv5n5f1b5c9.

Souza Santos, B. (Org.) (2005). A Globalização e as Ciências Sociais (3a ed.). Cortez.

Souza Santos, B. (2018). Construindo as Epistemologias do Sul: Antologia essencial. V.1. Clacso.

Vergès, F. (2005). Postface. In: Césaire, Aimé. Nègre je suis, nègre je resterai. Itinéraires du savoir. 